\title{
Pharmacokinetics and Pharmacodynamics of Huanglian-Houpo Decoction Based on Berberine Hydrochloride and Magnolol Against H1N1 Influenza Virus
}

\author{
Feng-ling Zhang ${ }^{1} \cdot$ Xiao-jie Yin ${ }^{1} \cdot$ Yun-liang Yan ${ }^{1} \cdot$ Qiao-feng Wu ${ }^{1}$ (D)
}

Accepted: 19 September 2021 / Published online: 12 October 2021

(c) The Author(s), under exclusive licence to Springer Nature Switzerland AG 2021

\begin{abstract}
Background and Objectives Huanglian-Houpo decoction (HH), which is recorded in the famous traditional Chinese medicine monograph "Puji Fang," contains two individual herbs, Huanglian (Rhizoma coptidis) and Houpo (Magnoliae officinalis cortex). It was regularly used to treat seasonal epidemic colds and influenzas in ancient China. Our laboratory discovered that $\mathrm{HH}$ has a significant anti-H1N1 influenza virus effect. However, no pharmacokinetic and pharmacodynamic data concerning the anti-H1N1 influenza virus activity of $\mathrm{HH}$ are available to date. In the current study, the concentration-time profiles of two major components of $\mathrm{HH}$, berberine and magnolol, in rat plasma were investigated.

Methods An integrate pharmacokinetic approach was developed for evaluating the holistic pharmacokinetic characteristics of berberine and magnolol from HH. Additionally, the inhibition rate and levels of IFN- $\beta$ in MDCK cells infected by influenza virus were analyzed. Data were calculated using 3p97 with pharmacokinetic analysis.

Results The estimated pharmacokinetic parameters were maximum plasma concentration $\left(C_{\max }\right) 0.9086 \mu \mathrm{g} / \mathrm{ml}$, area under the concentration-time curve (AUC) $347.74 \mu \mathrm{g} \cdot \mathrm{min} / \mathrm{ml}$, and time to reach $C_{\max }\left(T_{\max }\right) 64.69 \mathrm{~min}$ for berberine and $C_{\max }=$ $0.9843 \mu \mathrm{g} / \mathrm{ml}, \mathrm{AUC}=450.64 \mu \mathrm{g} \cdot \mathrm{min} / \mathrm{ml}, T_{\max }=56.86 \mathrm{~min}$ for magnolol, respectively. Furthermore, integrated pharmacokinetic and pharmacodynamic analysis showed that the highest plasma concentration, inhibition rate and interferon- $\beta$ (IFN- $\beta$ ) secretion of $\mathrm{HH}$ first increased and then weakened over time, reaching their peaks at $60 \mathrm{~min}$. The plasma concentration of $\mathrm{HH}$ is directly related to the anti-influenza virus effect.

Conclusion The results indicated that berberine and magnolol are the main active ingredients of $\mathrm{HH}$ related to its antiinfluenza virus effect, which is related to the improvement of IFN- $\beta$ secretion.
\end{abstract}

\section{Key Points}

Berberine and magnolol are the main active ingredients in $\mathrm{HH}$ related to its anti-influenza effect

HH's anti-influenza virus effect is related to the improvement of IFN- $\beta$ secretion

Qiao-feng Wu

wqfzfl@163.com

1 School of Pharmaceutical Sciences, Zhejiang Chinese Medical University, 548 Binwen Road, Binjiang District, Hangzhou 310053, Zhejiang, People's Republic of China

\section{Introduction}

The influenza virus is still an unpredictable threat to human health. It can evade immune system attacks because the influenza virus strain is not fixed [1]. Commercially available anti-influenza drugs, such as oseltamivir, zanamivir (neuraminidase inhibitors) and amantadine (M2 protein channel blockers), tend to induce side effects and drug resistance [2-4]. In recent years, researchers have been interested in efficient, safe and low drug-resistant drugs from natural plant resources to treat influenza. Traditional Chinese medicines (TCM), when combined with western medicines, play an important role in the prevention and treatment of global pandemic diseases such as H1N1 and SARS virus [5, 6]. Therefore, TCM has increasingly attracted the world's attention [7, 8]. 
Huanglian-Houpo decoction (HH), which is recorded in the famous TCM monograph "Puji Fang," contains two individual herbs, Huanglian (Coptidis rhizoma) and Houpo (Magnoliae officinalis cortex). It was regularly used to treat seasonal epidemic colds and influenzas in ancient China. Our laboratory discovered that HH has a significant antiH1N1 influenza virus effect. However, its pharmacological mechanism against influenza and pharmacokinetics are not clear.

Pharmacokinetic studies play an important role in explaining and predicting the efficacy of TCM and can also reveal the effective substances in TCM [9]. Furthermore, pharmacokinetic characteristics of drugs usually vary with the body condition and can be obtained by comparing the pharmacokinetics of drugs in bodies with different statuses $[10,11]$. We assumed that not all HH constituents that enter the plasma after oral administration exert a pharmacological effect. Therefore, we focused on the two most abundant constituents (berberine and magnolol; see Fig. 1) in rat plasma to clarify their pharmacokinetic behavior and pharmacological basis against the influenza virus.

\section{Materials and Methods}

\subsection{Chemicals and Reagents}

Berberine hydrochloride (batch no. 110713-200208) and magnolol (batch no. 050729) were purchased from the National Institutes for Food and Drug Control with $>98 \%$ purity. Methanol (batch no. 15015034) and acetonitrile (batch no. 15025018), HPLC grade, were purchased from Tedia Co. (Fairfield, OH, USA). Heparin sodium (batch no. 1203129-B) was purchased from Jiangsu Wan Bang Biochemical Pharmaceutical Co., Ltd. (Hangzhou, China). Oseltamivir phosphate capsules (batch no. B1345) were purchased from Roche Group (Basel, Switzerland). Dimethyl sulfoxide (batch no. AA20BA0001) was purchased from Shanghai Sheng Gong Company (Shanghai, China). PBS (batch no. 1646085), MEM medium (batch no. 1663805), glutamine (batch no. 1300075) and 0.25\% EDTA-pancreatin (batch no. 1300080) were all obtained from Gibco (USA). IFN- $\beta$ detection kits (batch no. 20130052TNFM) were purchased from R\&D (USA). All crude drugs were identified by Associate Professor Bing Yu, College of Pharmaceutical Science, Zhejiang Chinese Medical University, China. Standard preparation of HH (lot: 20170509) used in this study was according to the following methods: an aqueous extract of $\mathrm{HH}$ was prepared from $12 \mathrm{~g}$ Huanglian and $12 \mathrm{~g}$ Houpo. Crude herbs were extracted twice by refluxing for 1 h $30 \mathrm{~min}$ respectively with boiling water $(1: 10, \mathrm{~g} / \mathrm{ml})$. The extract was filtered, concentrated, freeze-dried and stored at $4{ }^{\circ} \mathrm{C}$ until use. Contents of berberine $(54.60 \mathrm{mg} / \mathrm{g})$ and magnolol $(34.50 \mathrm{mg} / \mathrm{g})$ were determined by high-performance liquid chromatography (HPLC).

\subsection{Animals}

Male ICR rats $(250 \pm 20 \mathrm{~g})$ were supplied by the Animal Experimental Center, Zhejiang Academy of Medical Sciences, China. The experimental animal protocols described were approved by the Medical Ethics Review Committee for Animal Experiments of Zhejiang Chinese Medical University (permit no. ZSLL-2016-191). Animals were maintained in air-conditioned animal quarters under the following conditions: temperature, $22 \pm 2{ }^{\circ} \mathrm{C}$; relative humidity, 50-60\%. All rats were fasted for $12 \mathrm{~h}$ before the experiment with free access to water. Mice were randomly divided into two groups with six rats in each group. Before oral administration, the spray-dried $\mathrm{HH}$ was dissolved in $0.5 \% \mathrm{CMC}-\mathrm{Na}$ at a concentration of $0.5 \mathrm{~g} / \mathrm{ml}$. Each animal in the administrated group was given a volume of $5.00 \mathrm{ml} / \mathrm{kg} \mathrm{HH}$, while the control group animals each received an equal volume of saline.

\subsection{Virus Strain}

H1N1: The influenza virus adapted to the rats was kindly supplied by Virus Research Institute, Zhejiang Provincial Center for Disease Control and Prevention. The TCID ${ }_{50}$ of influenza virus in rats was determined by Reed-Muench method ( TCID $_{50}$ is $\left.10^{5.2} / 0.1 \mathrm{ml}\right)$.
Fig. 1 Chemical structures of berberine (A) and magnolol (B)
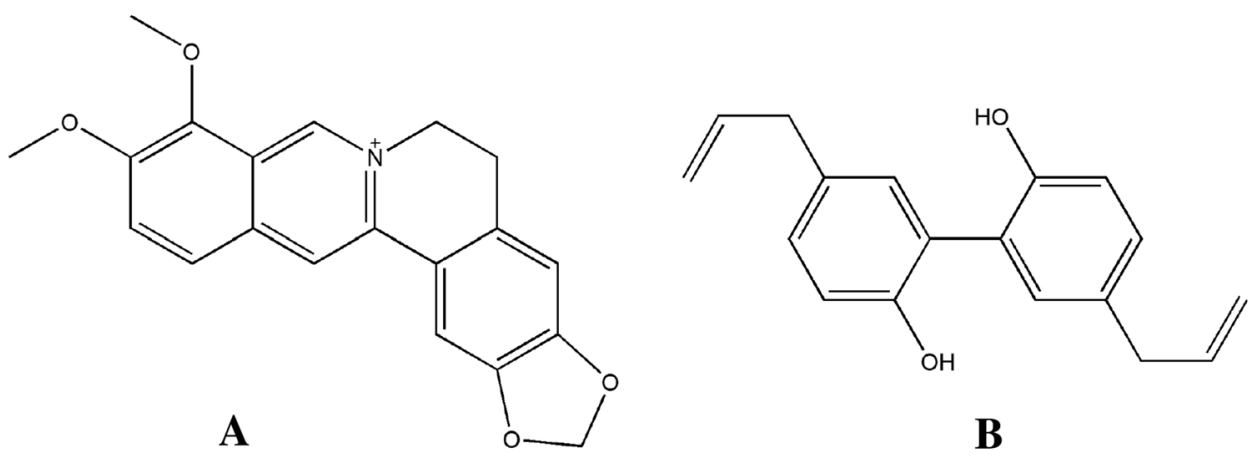

B 


\subsection{Method for Determining Berberine and Magnolol}

\subsubsection{High-Performance Liquid Chromatography Conditions}

Chromatography was performed on a Hypersil BDS $\mathrm{C}_{18}$ $(250 \mathrm{~mm} \times 4.6 \mathrm{~mm}, 5 \mu \mathrm{m})$. The mobile phase consisted of acetonitrile (solvent $\mathrm{A}$ ) and $0.1 \%$ phosphoric acid solution (triethylamine adjusted $\mathrm{pH} 4$ ) (solvent B) at a flow rate of 0.8 $\mathrm{ml} / \mathrm{min}$. The gradient elution program was as follows: $0-8$ min, 54-46\% A; 8-12 min, 46-37\% A; 12-20 min, 37-25\% A; 20-30 min, 25-20\% A. The injection volume was $25 \mu 1$. The detection wavelength was $265 \mathrm{~nm}$ and column temperature $30{ }^{\circ} \mathrm{C}$.

\subsubsection{Plasma Sample Preparation}

In the pharmacokinetic experiment ( $n=6 /$ group), $0.5 \mathrm{ml}$ blood samples were collected via the orbital vein into heparinized polythene tubes after administration of a single dose of $\mathrm{HH}$ at 10, 20, 30, 45, 60, 90, 120, 180, 240, 360, 480 and $720 \mathrm{~min}$ and then centrifuged at $4000 \mathrm{rpm}$ for 15 min. Plasma was transferred into clean tubes and stored at $-20^{\circ} \mathrm{C}$ until analysis. The previously prepared sample was loaded into the centrifuge tube followed by adding methanol-ethyl acetate $(3: 1)$. Extraction was conducted by vortexing vigorously for $3 \mathrm{~min}$ and then centrifuging at $4000 \mathrm{rpm}$ for $15 \mathrm{~min}$. The supernatant was obtained and transferred to another tube and dried under gentle $\mathrm{N}_{2}\left(37^{\circ} \mathrm{C}\right)$. The residue was reconstituted in $100 \mathrm{ml}$ methanol and then vortexed for $2 \mathrm{~min}$. Finally, the mixture was centrifuged at $10,000 \mathrm{rpm}$ for $15 \mathrm{~min}$. The supernatant $(10 \mu \mathrm{l})$ was injected for continuous HPLC analysis.

\subsection{Method Validation}

\subsubsection{Quantitative Control (QC) Sample Preparation}

Aliquots $(200 \mu \mathrm{l})$ of blank plasma with standards were added with methanol-ethyl acetate (3:1). The following steps were the same as in Sect. 2.4.1. QC samples of three concentration levels were prepared at concentrations of $1.900 \mu \mathrm{g} / \mathrm{ml}$ for berberine and $2.025 \mu \mathrm{g} / \mathrm{ml}$ for magnolol.

\subsubsection{Specificity}

Blank plasma and a plasma sample after administration of HH $(n=6)$ were prepared. As shown in Fig. 2, the retention time of berberine and magnolol in the plasma sample treated with $\mathrm{HH}$ was the same as for the blank plasma treated with berberine and magnolol standards. These data indicated that the analytical method was specific and could be used to accurately determine berberine and magnolol in the plasma sample.

\subsubsection{Calibration Curve and Lower Limits of Quantification and Detection}

Linearity was evaluated using freshly prepared spiked plasma samples, and the calibration curves were constructed. In addition, a blank (non-spiked sample) was run to discard the presence of interference. Plasma samples were spiked at concentrations of $6.080,3.040,1.520,0.760,0.3800$, 0.1900 and $0.0950 \mu \mathrm{g} / \mathrm{ml}$ for berberine hydrochloride and $6.480,3.240,1.620,0.8100,0.4050,0.2025$ and $0.1013 \mu \mathrm{g} /$ $\mathrm{ml}$ for magnolol. The calibration curves were constructed by plotting the berberine hydrochloride and magnolol peak areas and concentrations being used as $y$ and $x$ variables in a standard regression analysis. Good linearity was obtained from 0.0950 to $6.080 \mu \mathrm{g} / \mathrm{ml}$ for berberine hydrochloride; the regression equation was $Y=106.6 X+1.46(r=0.9990)$. For magnolol, $0.1013-6.480 \mu \mathrm{g} / \mathrm{ml}$ was obtainted; the regression equation was $Y=101.32 X+0.37(r=0.9973)$. The lower limits of detection (LLOD) and quantification (LLOQ) under the present HPLC conditions were determined based on the response at a signal-to-noise ratio of 3:1 and 10:1, respectively. The LLODs $(S / N=3)$ for berberine hydrochloride and magnolol were established at $0.0190 \mu \mathrm{g} / \mathrm{ml}$ and $0.0203 \mu \mathrm{g} / \mathrm{ml}$, and their LLOQs $(S / N=10)$ were established at $0.0380 \mu \mathrm{g} / \mathrm{ml}$ and $0.0405 \mu \mathrm{g} / \mathrm{ml}$.

\subsubsection{Precision and Accuracy}

To evaluate the intra- and inter-day precision (relative standard deviation, RSD) and accuracy (relative error, RE) of this method, different QC samples for each analyte were determined in six replicates for 3 consecutive days. The precision was expressed as RSD\%. The accuracy was expressed as the RE\% according to the equation: RE $(\%)=($ measured concentration-spiked concentration)/spiked concentration $\times$ $100 \%$. Table 1 shows the precision data for berberine hydrochloride and magnolol. All precision values were within the recommended limits of technical guidelines for chemical clinical pharmacokinetics.

\subsubsection{Recovery and Matrix Effect}

Different QC samples $(n=6)$ were used to evaluate the recovery and matrix effects of the analytes. The recovery of each analyte was calculated by comparing the amount of each analyte in the processed sample with that of the post-processed spiked sample. The matrix effect was evaluated by comparing the amount of each analyte in the postprocessed spiked sample with that of the pure standard solutions. As shown in Table 2, the extraction recoveries 
Fig. 2 HPLC chromatograms of berberine and magnolol: $\mathbf{A}$ blank plasma with berberine and magnolol standards, $\mathbf{B}$

blank plasma and $\mathbf{C}$ plasma

sample after oral administration of $\mathrm{HH}$
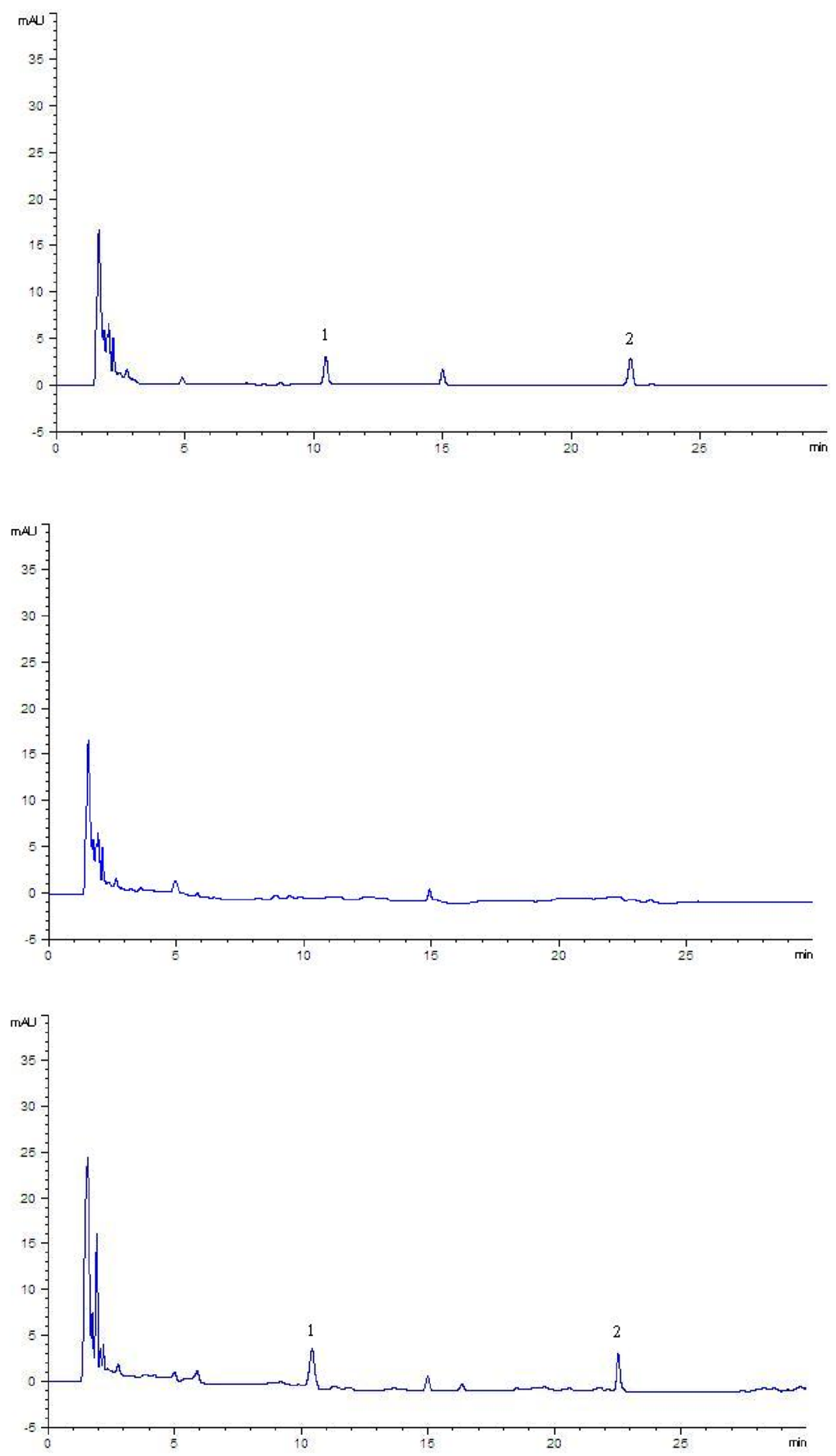
Table 1 Intra- and inter-day precision and accuracy for the determination of berberine hydrochloride and magnolol $(n=5)$

\begin{tabular}{|c|c|c|c|c|c|}
\hline \multirow{2}{*}{$\begin{array}{l}\text { Com- } \\
\text { pounds }\end{array}$} & \multirow{2}{*}{$\begin{array}{l}\text { Concen- } \\
\text { tration } \\
(\mu \mathrm{g} / \mathrm{ml})\end{array}$} & \multicolumn{2}{|c|}{ Intra-day (\%) } & \multicolumn{2}{|c|}{ Inter-day (\%) } \\
\hline & & Precision & Accuracy & Precision & Accuracy \\
\hline \multirow{3}{*}{$\begin{array}{c}\text { Berberine } \\
\text { hydro- } \\
\text { chloride }\end{array}$} & 0.1900 & 9.42 & -1.05 & 6.22 & -1.40 \\
\hline & 0.7600 & 5.78 & -7.10 & 5.48 & -8.68 \\
\hline & 3.0400 & 4.17 & -3.55 & 3.29 & -3.75 \\
\hline \multirow[t]{3}{*}{ Magnolol } & 0.2025 & 9.73 & 1.04 & 7.49 & 2.89 \\
\hline & 0.8100 & 3.43 & -5.43 & 3.74 & -6.83 \\
\hline & 3.2400 & 2.38 & -6.17 & 5.16 & -8.89 \\
\hline
\end{tabular}

Table 2 Recovery of berberine hydrochloride and magnolol after the extraction procedure $(n=5)$

\begin{tabular}{|c|c|c|c|c|c|}
\hline \multirow[t]{2}{*}{ Compounds } & \multirow[t]{2}{*}{$\begin{array}{l}\text { Concentra- } \\
\text { tion }(\mu \mathrm{g} / \mathrm{ml})\end{array}$} & \multicolumn{2}{|c|}{$\begin{array}{l}\text { Extraction recov- } \\
\text { ery }\end{array}$} & \multicolumn{2}{|c|}{ Matrix effect } \\
\hline & & Mean & $\operatorname{RSD}(\%)$ & Mean & $\operatorname{RSD}(\%)$ \\
\hline \multirow{3}{*}{$\begin{array}{l}\text { Berberine } \\
\text { hydrochlo- } \\
\text { ride }\end{array}$} & 0.1900 & 92.07 & 5.95 & 97.40 & 5.05 \\
\hline & 0.7600 & 97.38 & 3.95 & 94.73 & 4.94 \\
\hline & 3.0400 & 98.34 & 4.59 & 98.82 & 2.90 \\
\hline \multirow[t]{3}{*}{ Magnolol } & 0.2025 & 96.18 & 8.88 & 92.68 & 5.31 \\
\hline & 0.8100 & 99.45 & 4.37 & 94.42 & 3.16 \\
\hline & 3.2400 & 95.74 & 5.62 & 98.78 & 3.58 \\
\hline
\end{tabular}

determined for the analytes met the recommended limits of technical guidelines for chemical clinical pharmacokinetics [12].

\subsubsection{Stability}

The stability of each analyte was measured by determining different QC samples under four different conditions $(n=6)$. Short- and long-term stability was tested with different QC samples at $25{ }^{\circ} \mathrm{C}$ for $8 \mathrm{~h}$ and at $-20{ }^{\circ} \mathrm{C}$ for 15 days, respectively. Freeze-thaw stability was determined with different QC samples after carrying out three freezethaws. The data are presented in Table 3. They indicated that all the QC samples were stable during these tests, and there were no stability related problems during the routine analysis of samples for the pharmacokinetic study.

\subsection{Pharmacokinetic Study in Rats}

Plasma samples were obtained at each time point. The contents of berberine and magnolol peaks in biosamples were qualitatively and quantitatively analyzed by HPLC, respectively. For the pharmacokinetic studies, maximal concentration $\left(C_{\max }\right)$, time for maximal concentration $\left(T_{\max }\right)$, area under the concentration-time curve (AUC, $0-12 \mathrm{~h})$, half-life $\left(t_{1 / 2}\right)$, elimination rate constant $\left(K_{\mathrm{e}}\right)$ and total body clearance (CL) were estimated by compartmental methods using 3p97. The data were analyzed using one-way analysis of variance (SPSS 18.0).
Table 3 Stability of berberine hydrochloride and magnolol in plasma $(n=3)$

\begin{tabular}{lllr}
\hline Storage conditions & Compounds & Concentration & Mean \pm RSD \% \\
\hline Stability at room temperature for $8 \mathrm{~h}$ & Berberine hydrochloride & 0.19 & $0.17 \pm 8.83$ \\
& & 0.76 & $0.67 \pm 3.96$ \\
& & 3.04 & $2.98 \pm 2.10$ \\
Stability at $-20{ }^{\circ} \mathrm{C}$ for 15 days & Magnolol & 0.2025 & $0.197 \pm 7.78$ \\
& & 0.81 & $0.74 \pm 3.11$ \\
& & 3.24 & $2.83 \pm 2.48$ \\
Freeze-thaw stability & & 0.19 & $0.17 \pm 5.88$ \\
& & 0.76 & $0.7 \pm 6.23$ \\
& & 3.04 & $2.82 \pm 0.61$ \\
& Bagnolol & 0.2025 & $0.192 \pm 5.26$ \\
& & 0.81 & $0.76 \pm 4.75$ \\
& Magnolol & 3.24 & $2.97 \pm 3.25$ \\
& & 0.19 & $0.18 \pm 6.27$ \\
& & 0.76 & $0.67 \pm 3.74$ \\
& & 3.04 & $2.97 \pm 2.92$ \\
& & 0.2025 & $0.202 \pm 5.00$ \\
& & 0.81 & $0.75 \pm 4.24$
\end{tabular}




\subsection{Pharmacodynamics Study}

All plasma samples were diluted with cell maintenance solution to $25 \%, 12.5 \%$ and $6.25 \%$. The effects of drugcontaining plasma on the inhibition rate (\%) of MDCK cells that were infected by influenza virus were measured by MTT, and the secretions of IFN- $\beta$ in virus-infected cells were measured using the IFN- $\beta$ ELISA kit.

\subsection{Integrated Pharmacokinetic and Pharmacodynamic analysis}

As described by Li et al. and Zhu et al. [13-15], the integrated pharmacokinetic study was executed by calculating the concentration-time curve of berberine and magnolol, respectively ( $25 \%$ drug-containing plasma), and then using the following equations (Eqs. 1, 2, 3) to obtain the integrated concentration.

$\omega_{J}=\frac{\mathrm{AUC}_{J}}{\sum_{j=1}^{n} \mathrm{AUC}}$

$\sum_{j=1}^{n} \mathrm{AUC}=\mathrm{AUC}_{1}+\mathrm{AUC}_{2}+\ldots \mathrm{AUC}_{n}$

$C_{\text {int }}=\sum_{j=1}^{n} \omega_{j} \times C_{J}$

The weighting coefficient for berberine and magnolol was calculated using Eqs. 1 and 2. The integrated concentrations $\left(C_{\text {int }}\right)$ were then calculated by Eq. 3 .

To study the integrated pharmacodynamics of $\mathrm{HH}$, the curve between the integrated plasma concentration of berberine and magnololand calculated above versus the inhibition rate and the curve between the integrated plasma concentration versus INF- $\beta$ secretion were executed.

\subsection{Data Analysis}

The plasma concentrations of berberine and magnolol were evaluated. $3 \mathrm{p} 97$ was used to process the concentration data and for compartment model fitting, and then all pharmacokinetic parameters were determined. The following pharmacokinetic parameters were calculated: maximum plasma concentration $\left(C_{\max }\right)$ and time of maximum concentration $\left(T_{\max }\right)$, area under the curve (AUC), mean residence time (MRT), half-life $\left(T_{1 / 2}\right)$ and clearance $(\mathrm{CL})$. Quantitative data were expressed as mean \pm standard

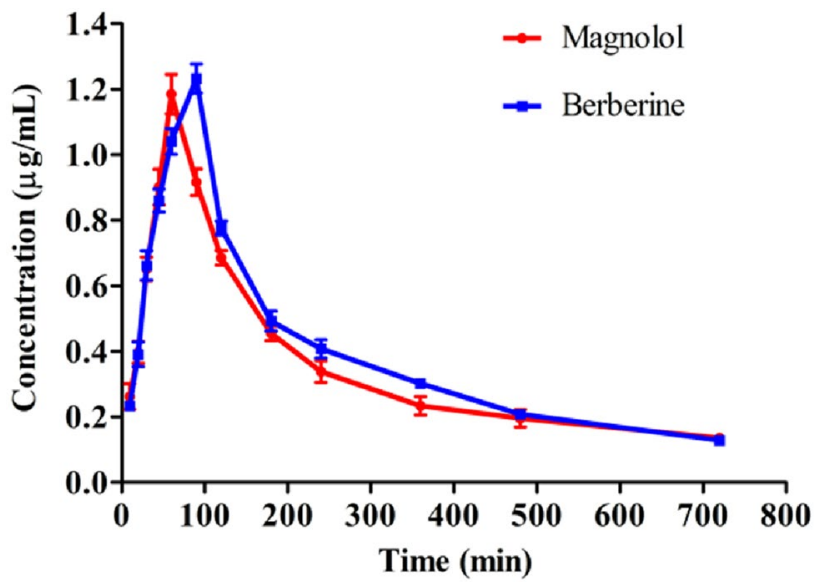

Fig. 3 Mean \pm SD plasma concentration-time curves of berberine and magnolol in normal rats $(n=6)$.

Table 4 Pharmacokinetic parameters of berberine and magnolol in normal rats (mean $\pm \mathrm{SD}, n=6)$

\begin{tabular}{lcc}
\hline Parameters & \multicolumn{1}{l}{ Berberine } & \multicolumn{1}{l}{ Magnolol } \\
\hline$A(\mu \mathrm{g} / \mathrm{ml})$ & $3.2209 \pm 0.1934$ & $3.0421 \pm 0.2815$ \\
$\alpha(1 / \mathrm{min})$ & $0.0120 \pm 0.0004$ & $0.0131 \pm 0.0006$ \\
$B(\mu \mathrm{g} / \mathrm{ml})$ & $0.3151 \pm 0.0298$ & $0.2228 \pm 0.0404$ \\
$\beta(1 / \mathrm{min})$ & $0.0014 \pm 0.0002$ & $0.0007 \pm 0.0001$ \\
$K_{\mathrm{a}}(1 / \mathrm{min})$ & $0.0233 \pm 0.0010$ & $0.0270 \pm 0.0007$ \\
$T_{\text {lag }}(\mathrm{min})$ & $6.66 \pm 0.36$ & $6.7946 \pm 1.0388$ \\
$T_{1 / 2, \alpha}(\mathrm{min})$ & $57.69 \pm 1.58$ & $52.85 \pm 2.53$ \\
$T_{1 / 2, \beta}(\mathrm{min})$ & $513.78 \pm 82.45$ & $1072.75 \pm 95.96$ \\
$T_{1 / 2, K \mathrm{a}}(\mathrm{min})$ & $29.78 \pm 1.23$ & $25.69 \pm 0.65$ \\
$K_{21}(1 / \mathrm{min})$ & $0.0031 \pm 0.0004$ & $0.0022 \pm 0.0003$ \\
$K_{10}(1 / \mathrm{min})$ & $0.0054 \pm 0.0003$ & $0.0039 \pm 0.0002$ \\
$K_{12}(1 / \mathrm{min})$ & $0.0049 \pm 0.0004$ & $0.0077 \pm 0.0004$ \\
$\mathrm{AUC}(\mu \mathrm{g} \cdot \mathrm{min} / \mathrm{ml})$ & $347.74 \pm 31.27$ & $450.64 \pm 0.2815$ \\
$\mathrm{AUMC}(\mu \mathrm{g} \cdot \mathrm{min} / \mathrm{ml})$ & $125645.9 \pm 8181.6$ & $180648.1 \pm 32404.6$ \\
$\mathrm{MRT}(\mathrm{min})$ & $379.64 \pm 10.99$ & $534.54 \pm 86.26$ \\
$\mathrm{CL}(\mathrm{ml} / \mathrm{min})$ & $0.3220 \pm 0.0292$ & $0.3038 \pm 0.0197$ \\
$T_{\max }(\mathrm{min})$ & $64.69 \pm 1.93$ & $56.86 \pm 1.22$ \\
$C_{\max }(\mu \mathrm{g} / \mathrm{ml})$ & $0.9086 \pm 0.0436$ & $0.9843 \pm 0.0294$ \\
\hline
\end{tabular}

deviation (SD) when normally distributed. $p<0.05$ was considered statistically significant.

\section{Results}

\subsection{Pharmacokinetic Study}

The validated HPLC method was successfully applied to the pharmacokinetic study and simultaneous measurement of two compounds in plasma for $12 \mathrm{~h}$ after oral administration 
of $5.00 \mathrm{ml} / \mathrm{kg} \mathrm{HH}$. The plasma concentration-time curve profiles of berberine and magnolol in normal rats are shown in Fig. 3. The obtained pharmacokinetic compartment model was calculated, which pertains to the two-compartment model for the pharmacokinetic parameter calculation using 3p97. As shown in Table 4, the estimated pharmacokinetic parameters were $C_{\max }=0.9086 \mu \mathrm{g} / \mathrm{ml}, T_{\max }=64.69 \mathrm{~min}$, $\mathrm{AUC}=347.74 \mu \mathrm{g} \cdot \mathrm{min} / \mathrm{ml}$ and $\mathrm{CL}=0.3220 \mathrm{ml} / \mathrm{min}$ for berberine and $C_{\max }=0.9843 \mu \mathrm{g} / \mathrm{ml}, T_{\max }=56.86 \mathrm{~min}, \mathrm{AUC}=$ $450.64 \mu \mathrm{g} \cdot \mathrm{min} / \mathrm{ml}$ and $\mathrm{CL}=0.3038 \mathrm{ml} / \mathrm{min}$ for magnolol.

\subsection{Pharmacodynamic Study}

As shown in Table 5 and Fig. 4A, the results indicated that all drug-containing plasma (25\%, $12.5 \%$ and $6.25 \%)$ directly inhibited virus proliferation and exhibited a dose effect. The results also indicated that the anti-influenza virus effect of all drug-containing plasma first increased and then weakened over time, and the best effect was at $60 \mathrm{~min}$.

There are two main anti-influenza pathways of Chinese herbal medicine: directly killing viruses by inhibiting proliferation or indirectly killing viruses by inducing interferon (IFN) secretion and regulating human immune functions to inhibit virus proliferation [16-18]. Type I interferons such as IFN- $\alpha / \beta$ are key mediators of the innate immune response against influenza virus infections [19]. Several previous studies showed that IFNs exert antiviral activity against influenza virus infection. Pretreatment with IFN- $\alpha / \beta$ significantly suppressed the replication of H1N1 virus [20]. Data in Table 5 show that $25 \%$ drug-containing plasma exhibited the best inhibiting virus proliferation effect. Thus, we selected IFN- $\beta$ secretion at $25 \%$ drug-containing plasma concentration as the indicator to preliminarily reveal the anti-influenza virus mechanism of $\mathrm{HH}$.
Table 5 Inhibition rate of drugcontaining plasma on virus proliferation
Fig. 4 Effect-time curves of inhibition rate (A) and IFN- $\beta$ secretion (B) of MDCK cells infected by influenza virus \pm . Values are mean \pm SD

\begin{tabular}{|c|c|c|c|c|}
\hline \multirow[t]{2}{*}{ Groups } & \multirow[t]{2}{*}{$\mathrm{T} / \mathrm{min}$} & \multicolumn{3}{|c|}{ Inhibition rate $(\%)$} \\
\hline & & $25 \%$ & $12.5 \%$ & $6.25 \%$ \\
\hline \multirow[t]{11}{*}{ Drug-containing plasma } & 10 & $23.50 \pm 1.99$ & $23.22 \pm 1.06$ & $23.74 \pm 1.57$ \\
\hline & 20 & $33.26 \pm 1.77 *$ & $26.32 \pm 2.21 *$ & $26.01 \pm 1.54 *$ \\
\hline & 30 & $43.68 \pm 2.22 *$ & $34.97 \pm 1.48^{*}$ & $30.97 \pm 2.02 *$ \\
\hline & 45 & $56.79 \pm 2.86^{*}$ & $37.45 \pm 1.54 *$ & $33.85 \pm 1.22 *$ \\
\hline & 60 & $72.04 \pm 2.78^{*}$ & $48.64 \pm 2.69^{*}$ & $44.33 \pm 1.02 *$ \\
\hline & 90 & $56.42 \pm 1.19^{*}$ & $45.23 \pm 1.19 *$ & $36.05 \pm 1.69^{*}$ \\
\hline & 180 & $44.42 \pm 3.80^{*}$ & $33.69 \pm 1.69 *$ & $30.25 \pm 1.58 *$ \\
\hline & 240 & $37.69 \pm 2.55^{*}$ & $30.32 \pm 1.47 *$ & $26.10 \pm 1.52$ \\
\hline & 360 & $32.46 \pm 1.12 *$ & $29.42 \pm 1.22 *$ & $24.27 \pm 1.07$ \\
\hline & 480 & $29.39 \pm 1.21^{*}$ & $25.02 \pm 1.45$ & $23.19 \pm 1.87$ \\
\hline & 720 & $26.78 \pm 0.79$ & $24.02 \pm 1.67$ & $23.16 \pm 1.47$ \\
\hline Blank plasma & - & $24.05 \pm 1.89$ & $23.50 \pm 2.16$ & $23.25 \pm 1.63$ \\
\hline Positive control & - & $66.15 \pm 1.55^{*}$ & & \\
\hline
\end{tabular}

Data are expressed as mean $\pm \mathrm{SD}(n=4)$

$* p<0.05$ compared with blank plasma
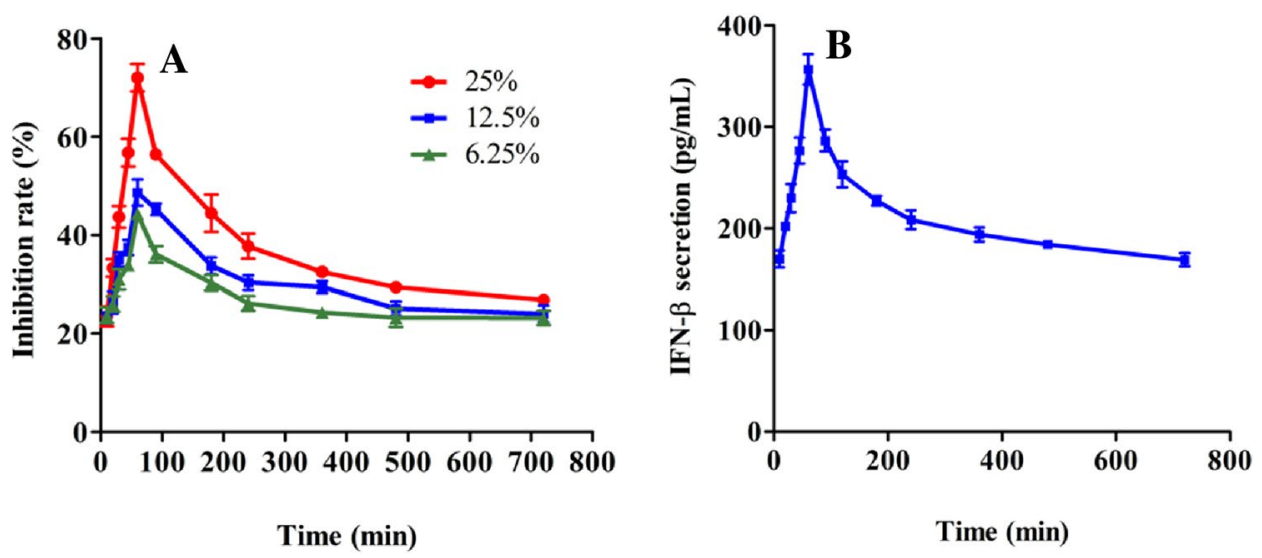
Table 6 Effect of drug-containing plasma on IFN- $\beta$ secretion in MDCK cells infected by influenza virus

\begin{tabular}{llll}
\hline Groups & \multicolumn{2}{l}{ T (min) Concentration } & $\begin{array}{l}\text { IFN- } \beta \text { secretion }(\mathrm{pg} / \\
\mathrm{ml})\end{array}$ \\
\hline $\begin{array}{l}\text { Drug-containing } \\
\text { plasma }\end{array}$ & 10 & $25 \%$ & $169.63 \pm 8.42$ \\
& 20 & $25 \%$ & $201.89 \pm 2.55^{*}$ \\
& 30 & $25 \%$ & $229.67 \pm 13.68^{*}$ \\
& 45 & $25 \%$ & $276.47 \pm 12.67^{*}$ \\
& 60 & $25 \%$ & $356.60 \pm 14.83^{*}$ \\
& 90 & $25 \%$ & $286.51 \pm 10.71^{*}$ \\
& 120 & $25 \%$ & $253.18 \pm 12.89^{*}$ \\
& 180 & $25 \%$ & $227.11 \pm 4.70^{*}$ \\
& 240 & $25 \%$ & $208.30 \pm 9.14^{*}$ \\
& 360 & $25 \%$ & $193.99 \pm 6.94^{*}$ \\
& 480 & $25 \%$ & $183.95 \pm 3.30^{*}$ \\
Blank plasma & - & $25 \%$ & $168.77 \pm 6.4$ \\
Normal group & - & - & $168.56 \pm 8.89$ \\
Virus-infected group & - & - & $168.99 \pm 9.90$ \\
Positive group & - & $10 \mu \mathrm{g} / \mathrm{ml}$ & $168.13 \pm 8.67$ \\
\hline
\end{tabular}

Data are expressed as mean $\pm \operatorname{SD}(n=4)$

$* p<0.05$ compared with virus-infected group

Table 7 Integrated plasma concentration of berberine and magnolol (mean $\pm \mathrm{SD}, n=6)$

\begin{tabular}{ll}
\hline $\mathrm{T}(\mathrm{min})$ & $\begin{array}{l}\text { Integrated plasma } \\
\text { concentration }(\mu \mathrm{g} / \\
\mathrm{ml})\end{array}$ \\
\hline 10 & $0.2496 \pm 0.0263$ \\
20 & $0.3940 \pm 0.0165$ \\
30 & $0.6560 \pm 0.0317$ \\
45 & $0.8832 \pm 0.0347$ \\
60 & $1.1218 \pm 0.0490$ \\
90 & $1.0540 \pm 0.0419$ \\
120 & $0.7249 \pm 0.0142$ \\
180 & $0.4708 \pm 0.0194$ \\
240 & $0.3682 \pm 0.0279$ \\
360 & $0.2634 \pm 0.0169$ \\
480 & $0.2010 \pm 0.0171$ \\
720 & $0.1327 \pm 0.0071$ \\
\hline
\end{tabular}

As shown in Table 6 and Fig. 4B, like the inhibition rate of drug-containing plasma, compared with the virusinfected group, the secretion of IFN- $\beta$ in the virus-infected cells significantly increased $(p<0.05)$ in the drug-containing plasma group, except for the time points of $10 \mathrm{~min}$ and $720 \mathrm{~min}$, and the highest IFN- $\beta$ secretion also occurred at $60 \mathrm{~min}$

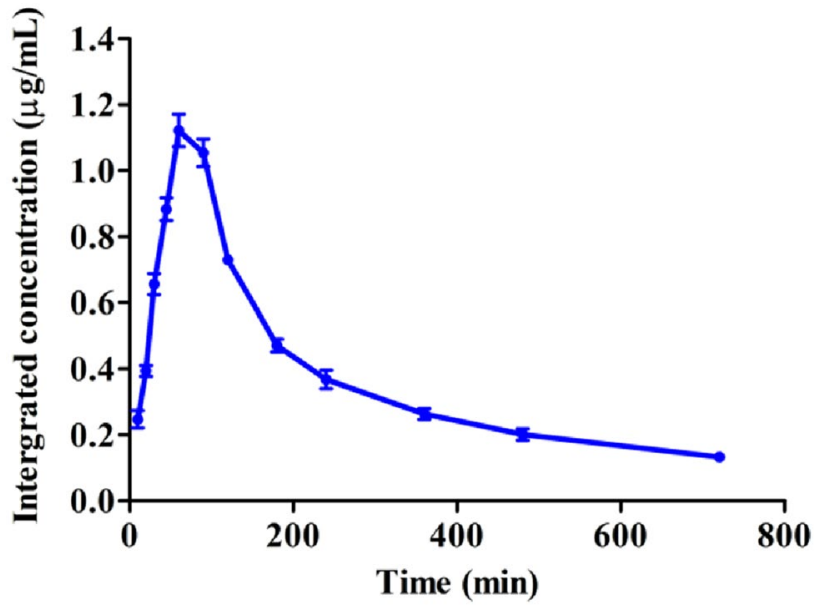

Fig. 5 Integrated plasma concentration-time curves of berberine and magnolol in normal rats. Data are expressed as mean $\pm \operatorname{SD}(n=6)$

\subsection{Integrated Pharmacokinetic and Pharmacodynamic Analysis}

As shown in Table 7 and Fig. 5, the results indicated that the integrated plasma concentration of berberine and magnolol first increased and then weakened over time and reached its peak at $60 \mathrm{~min}$.

The curve between the integrated plasma concentration of berberine and magnolol and versus inhibition rate and the curve between the integrated plasma concentration of berberine and magnolol versus INF- $\beta$ secretion are shown in Fig. 6. The results showed that the integrated plasma concentration of berberine and magnolol is positively correlated with the virus inhibition rate and INF- $\beta$ secretion. The $\mathrm{R}^{2}$ values obtained by linear regression were 0.9196 and 0.9205 , respectively. The results indicated that there is a good correlation between pharmacokinetics and pharmacodynamics.

\section{Discussion}

The therapeutic efficacy of TCM is based on the combined action of constituents that simultaneously regulate multiple targets. In addition, TCM shows lower adverse reactions and toxicity. Thus, it provides new treatment opportunities $[21,22]$. Pharmacokinetics and pharmacodynamics play an important role in evaluation of drug actions and are useful in elucidating the mechanism of TCM formulae [23-25]. However, TCM is a complex system, and a single component is not sufficient to characterize its pharmacokinetic process in vivo. The active prototypes of TCM and their metabolites in vivo constitute the material foundation of medicinal effectiveness [26]. It is very difficult to study the relationship between a TCM's pharmacokinetic behavior and its 
Fig. 6 Inhibition rate-integrated plasma concentration curves (A) and IFN- $\beta$ secretion-integrated plasma concentration curves (B). Data are expressed as mean $\pm \mathrm{SD}(n=6)$

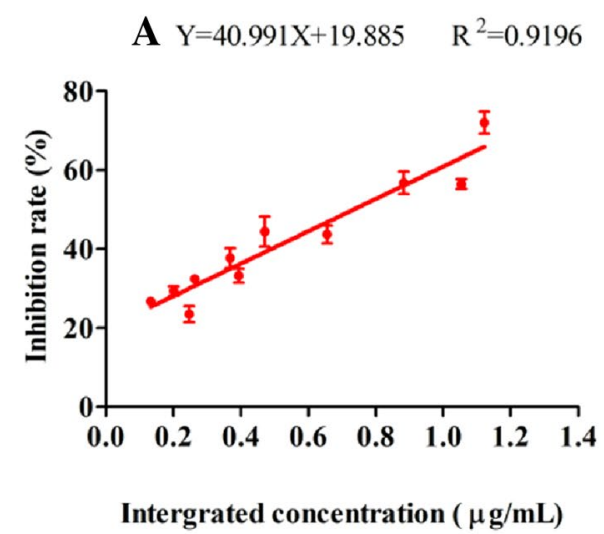

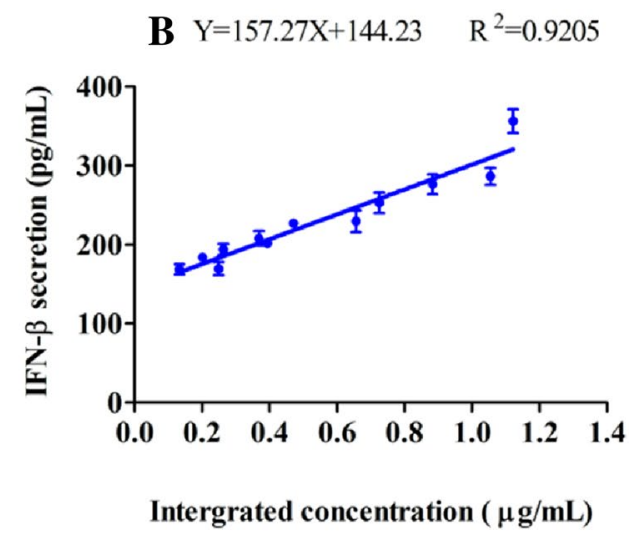

effects. We assumed that not all $\mathrm{HH}$ constituents that enter the plasma after oral administration exert a pharmacological effect. Therefore, we focused on the two most abundant constituents, berberine and magnolol, in rat plasma to clarify the relationship between the pharmacokinetic and pharmacodynamic behaviors against influenza virus.

Based on this assumption, the validated HPLC method was successfully applied to the pharmacokinetic study of HH. Relevant pharmacokinetic parameters $\left(C_{\max }=0.9086\right.$ $\mu \mathrm{g} / \mathrm{ml}, T_{\max }=64.69 \mathrm{~min}, \mathrm{AUC}=347.74 \mu \mathrm{g} \cdot \mathrm{min} / \mathrm{ml}$ for berberine and $C_{\max }=0.9843 \mu \mathrm{g} / \mathrm{ml}, T_{\max }=56.86 \mathrm{~min}, \mathrm{AUC}=$ $450.64 \mu \mathrm{g} \cdot \mathrm{min} / \mathrm{ml}$ for magnolol, respectively; Table 4) were obtained by calculation using $3 \mathrm{p} 97$. Interestingly, the plasma concentration-time curve profiles show that the concentrations of berberine are especially high, $>200 \mathrm{ng} / \mathrm{ml}$, for all time points. This is not consistent with its low bioavailability and what is reported in the literature, with low ng/ $\mathrm{ml}$ values, usually several to $\leq 30 \mathrm{ng} / \mathrm{ml}$. Some reports in the literature showed that one kind of herb combined with another will change the bioavailability of its active ingredients. For example, Li et al. studied the pharmacokinetics of pure berberine, berberine in Coptidis rhizoma (CRE) and berberine in Coptidis rhizoma-Glycyrrhizae radix et rhizoma (CR-GRE) extracts. The results revealed that due to the different intestinal absorption, the bioavailability of CRE and CR-GRE is much lower than that of pure berberine [27]. Zhang et al.'s research indicated that Gancao was able to reduce the intestinal absorption of berberine in Huanglian through reductions in the extracted amount, solubility and release from the herb extract [28]. Modern natural medicine research shows that the main ingredients in HuanglianHoupu decoction are berberine and magnolol. Berberine is a quaternary ammonium alkaloid, and magnolol is a biphenol compound. When the two act together, magnolol promotes the absorption of berberine. Meng et al. studied the pharmacokinetics of berberine in Huanglian extracts and berberine in Huanglian-Houpo extracts. The results revealed that, compared with Huanglian extracts, the berberine concentration of Huanglian-Houpo extracts $\left(C_{\max }: 162 \mathrm{ng} / \mathrm{ml}\right)$ in rat plasma is much higher than that of Huanglian extracts $\left(C_{\max }: 67 \mathrm{ng} / \mathrm{ml}\right)$. This shows that Houpo can improve the bioavailability of berberine in Huanglian [29]. These results are consistent with our research showing that the concentrations of berberine are especially high, $>200 \mathrm{ng} / \mathrm{ml}$, for all the time points.

For a long time, the complex in vivo process of TCM has made pharmacokinetic research on it difficult. TCMs have been widely claimed to act in a holistic mode of multiple components that are multi-target and multi-channel. Therefore, research on the isolated pharmacokinetic behavior of one or several components is not enough to express the overall pharmacokinetic behavior of TCM, let alone explore the relationship between dose and response [15]. Pioneering work in the field explored a novel integrated pharmacokinetic approach to pharmacokinetic research of TCM [13, 14]. An AUC-weighting approach based on the same type constituents derived from one TCM herb has been created to obtain the holistic pharmacokinetic properties, and this integral pharmacokinetic method has been applied successfully to link pharmacokinetic and pharmacodynamic data [30, 31].

Based on the AUC-weighting approach mentioned above, the integrated plasma concentration-time curves (Fig. 5) could be obtained from the pharmacokinetic parameters of berberine and magnolol. The results showed that the integrated plasma concentration of berberine and magnolol first increased and then weakened over time and reached its peak at $60 \mathrm{~min}$. The pharmacodynamic data in Table 5 and Fig. 4A show that the highest inhibition rate of drug-containing plasma also occurs at $60 \mathrm{~min}$. The result indicates that the peaks of the maximum effect and plasma concentration occur at the same time point. Meanwhile, the pharmacodynamic data (Fig. 6) showed that the integrated plasma concentration of berberine and magnolol is positively correlated with the virus inhibition rate. As the plasma concentration increases, the strength of the effect also increases. There is no time advance or lag between the effect and the time, and it is completely 
parallel and corresponding. That is, the plasma concentration is directly related to the pharmacological effects.

To preliminarily reveal the anti-influenza virus mechanism of $\mathrm{HH}$, the IFN- $\beta$ secretion was determined. Compared with the virus control group, the IFN- $\beta$ secretion significantly increased in the $\mathrm{HH}$-containing plasma group except for the $10 \mathrm{~min}$ and $720 \mathrm{~min}$ time points. Figure 4 also showed that the E-T curves of inhibition rate and IFN- $\beta$ secretion were extremely similar, and both the highest inhibition rate and IFN- $\beta$ secretion occurred at $60 \mathrm{~min}$.

All the results indicated that berberine and magnolol are the main active anti-influenza ingredients in $\mathrm{HH}$, and the anti-influenza virus effect was related to the improvement of IFN- $\beta$ secretion.

\section{Conclusion}

In summary, in this study, a rapid, sensitive, selective and specific HPLC method was developed and validated for the simultaneous determination of berberine and magnolol in rat plasma and successfully employed for the pharmacokinetic study of HH. Furthermore, an integrated pharmacokinetic approach was developed for evaluating the holistic pharmacokinetic characteristics of berberine and magnolol in $\mathrm{HH}$. We concluded that berberine and magnolol are the main active anti-influenza ingredients in $\mathrm{HH}$. The plasma concentration of $\mathrm{HH}$ is directly related to the anti-influenza virus effect, and the anti-influenza virus effect is related to the improvement of IFN- $\beta$ secretion. These observations indicate that TCMs usually are most effective as multi-component preparations. Because of the complexity of chemical constituents in TCM formulations, pharmacokinetic study of active constituents in TCM is essential to illustrate their action mechanism. Thus, this work will provide helpful information for the pharmacokinetic evaluation of multiple constituents of indigenous medicines.

\section{Declarations}

Funding This work was supported by the Science Technology Department of Zhejiang Province (2011C22004), National Natural Science Foundation of China (81274030/H2803) and Zhejiang Provincial Natural Science Foundation of China (LY15H290003/LY18H280007).

Conflicts of Interest All authors declare that they have no conflict of interest.

Ethics Approval The study was reviewed and approved by the Medicine Ethics Review Committee for Animal Experiments of Zhejiang Chinese Medical University (resolution no. ZSLL-2016-191).

Consent to Participate Not applicable.
Consent for Publication Not applicable.

Availability of Data and Material The authors confirm that the data supporting the findings of this study are available within the article.

Authors' Contributions F-1Z, X-jY and Q-fW contributed to planning, design, data collection and data analysis. F-1Z, X-jY, Y-lY and Q-fW contributed to interpretation of the results, drafting and revising the manuscript and agree to be accountable for all aspects of the work. $\mathrm{F}-\mathrm{lZ}$ and $\mathrm{X}-\mathrm{jY}$ contributed equally to this work.

Code Availability Not applicable

\section{References}

1. Alenquer M, Vale-Costa S, Etibor TA, Ferreira F, Sousa AL, Amorim MJ. Influenza A virus ribonucleoproteins form liquid organelles at endoplasmic reticulum exit sites. Nat Commun. 2019;10(1):1629. https://doi.org/10.1038/s41467-019-09549-4.

2. Jackson RJ, Cooper KL, Tappenden P, Rees A, Simpson EL, Read RC, Nicholson KG. Oseltamivir, zanamivir and amantadine in the prevention of influenza: a systematic review. J Infect. 2011;62(1):14-25. https://doi.org/10.1016/j.jinf.2010.10.003.

3. Han X, Zhang DK, Guo YM, Feng WW, Dong Q, Zhang CE, Zhou YF, Liu Y, Wang JB, Zhao YL, Xiao XH, Yang M. Screening and evaluation of commonly-used anti-influenza Chinese herbal medicines based on anti-neuraminidase activity. Chin J Nat Med. 2016;14(10):794-800. https://doi.org/10.1016/S18755364(16)30095-4.

4. Kumar B, Asha K, Khanna M, Ronsard L, Meseko CA, Sanicas $\mathrm{M}$. The emerging influenza virus threat: status and new prospects for its therapy and control. Arch Virol. 2018;163:1-14. https://doi. org/10.1007/s00705-018-3708-y.

5. Li JH, Wang RQ, Guo WJ, Li JS. Efficacy and safety of traditional Chinese medicine for the treatment of influenza A (H1N1): a meta-analysis. J Chin Med Assoc. 2016;79(5):281-91. https:// doi.org/10.1016/j.jcma.2015.10.009.

6. Liu X, Zhang M, He L, Li Y. Chinese herbs combined with western medicine for severe acute respiratory syndrome (SARS). Cochrane DB Syst Rev. 2012;10:CD004882. https://doi.org/10. 1002/14651858.CD004882.

7. Ma LL, Ge M, Wang HQ, Yin JQ, Jiang JD, Li YH. Antiviral activities of several oral traditional Chinese medicines against influenza viruses. Evid-based Complement Alt Med. 2015;367250:1-9. https://doi.org/10.1155/2015/367250.

8. Zhang HH, Yu WY, Li L, Wu F, Chen Q, Yang Y, Yu CH. Protective effects of diketopiperazines from Moslae Herba against influenza A virus-induced pulmonary inflammation via inhibition of viral replication and platelets aggregation. J Ethnopharmacol. 2018;215:156-66. https://doi.org/10.1016/j.jep.2018.01.005.

9. Sun H, Dong T, Zhang A, Yang J, Yan G, Sakurai T, Wu X, Han $Y$, Wang X. Pharmacokinetics of hesperetin and naringenin in the Zhi Zhu Wan, a traditional Chinese medicinal formulae, and its pharmacodynamics study. Phytother Res. 2013;27(9):1345-51. https://doi.org/10.1002/ptr.4867.

10. Guan J, Zhang X, Feng B, Zhao D, Zhao T, Chang S, Wang L, Zhu H. Simultaneous determination of ferulic acid and gastrodin of Tianshu capsule in rat plasma by ultra-fast liquid chromatography with tandem mass spectrometry and its application to a comparative pharmacokinetic study in normal and migraine rats. J Sep Sci. 2017;40:4120-7. https://doi.org/10.1002/jssc.201700665. 
11. Zhu L, Li JY, Zhang YM, Kang HX, Chen H, Su H, Li J, Tang WF. Pharmacokinetics and pharmacodynamics of Shengjiang decoction in rats with acute pancreatitis for protecting against multiple organ injury. World J Gastroenterol. 2017;23(46):816981. https://doi.org/10.3748/wjg.v23.i46.8169.

12. Bhattaram VA, Graefe U, Kohlert C, Veit M, Derendorf H. Pharmacokinetics and bioavailability of herbal medicinal products. Phytomedicine. 2002;9(3):1-33. https://doi.org/10.1078/ 1433-187x-00210.

13. Li XX, Li CB, Ji XP, Song ZF, Wang LH, Zhang J, Zhang Y. Huang-lian-jie-du-tang inhibits myocardial remodeling in a rat model of metabolic syndrome. J Ethnopharmacol. 2008;119(2):259-65. https://doi.org/10.1016/j.jep.2008.07.019.

14. Li XY, Hao HP, Wang GJ, Sun JG, Liang Y, Xie L, Zheng YT. Integrated pharmacokinetic study of multiple effective components contained in total panax notoginsenosides. Chin J Nat Med. 2008;6(5):377-81. https://doi.org/10.3724/SP.J.1009.20008. 00377.

15. Zhu HX, Qian ZL, Li H, Guo LW, Pan LM, Zhang QC, Tang YP. Integrated pharmacokinetics of major bioactive components in mcao rats after oral administration of huang-lian-jie-du-tang. J Ethnopharmacol. 2012;141(1):158-69. https://doi.org/10.1016/j. jep.2012.02.014.

16. Tian L, Wang ZY, Wu H, Wang S, Wang Y, Wang Y, Xu JW, Wang LY, Qi FC, Fang ML, Yu DH, Fang XX. Evaluation of the anti-neuraminidase activity of the traditional Chinese medicines and determination of the anti-influenza A virus effects of the neuraminidase inhibitory TCMs in vitro and in vivo. J Ethnopharmacol. 2011;137(1):534-42. https://doi.org/10.1016/j.jep.2011.06. 002.

17. Hsu ACY, Parsons K, Barr I, Lowther S, Middleton D, Hansbro PM, Wark PAB. Critical role of constitutive type I interferon response in bronchial epithelial cell to influenza infection. PLoS One. 2012;7(3): e32947. https://doi.org/10.1371/journal.pone. 0032947.

18. Wang ZQ, Zhu Y. Anti-respiratory passage virus of Chinese herbal medicine. Health. 2010;2(12):1397-400. https://doi.org/ 10.4236/health.2010.212207.

19. Ilyushina NA, Donnelly RP. In vitro anti-influenza A activity of interferon (IFN)-lambda 1 combined with IFN-beta or oseltamivir carboxylate. Antivir Res. 2014;111:112-20. https://doi.org/10. 1016/j.antiviral.2014.09.008.

20. Osterlund P, Pirhonen J, Ikonen N, Ronkko E, Strengell M, Makela SM, Broman M, Hamming OJ, Hartmann R, Ziegler T, Julkunen I. Pandemic H1N1 2009 influenza A Virus induces weak cytokine responses in human macrophages and dendritic cells and is highly sensitive to the antiviral actions of interferons. J Virol. 2010;84(3):1414-22. https://doi.org/10.1128/JVI.01619-09.

21. Cao YY, Yan RY, Yang LX, Guo J, Liu HL, Zhang JY, Yang B, Huang LQ. Quality evaluation of Semen oroxyli based on the determination of multiple components with a single reference standard. J Chromatogr Sci. 2013;51:477-84. https://doi.org/10. 1093/chromsci/bms 166.
22. Li YB, Li YM, Lu WL, Li HB, Wang YM, Luo HM, Wu YY, Dong WY, Bai G, Zhang YJ. Integrated network pharmacology and metabolomics analysis of the therapeutic effects of $\mathrm{Zi}$ Dian Fang on immune thrombocytopenic purpura. Front Pharmacol. 2018;9:597. https://doi.org/10.3389/fphar.2018.00597.

23. Ding X, Sun YM, Wang Q, Pu TT, Li XH, Pan YQ, Yang Y. Pharmacokinetics and pharmacodynamics of glycyrrhetinic acid with Paeoniflorin after transdermal administration in dysmenorrhea model mice. Phytomedicine. 2016;23(8):864-71. https://doi. org/10.1016/j.phymed.2016.05.005.

24. Hou ML, Lin CH, Lin LC, Tsai TH. The Drug-Drug Effects of Rhein on the pharmacokinetics and pharmacodynamics of clozapine in rat brain extracellular fluid by in vivo microdialysis. J Pharmacol Exp Ther. 2015;355(1):125-34. https://doi.org/10. 1124/jpet.115.225763.

25. Tang XL, Zhao HH, Jiang W, Zhang S, Guo S, Gao XB, Yang B, Shi L, Liu LN. Pharmacokinetics and pharmacodynamics of citrus peel extract in lipopolysaccharide-induced acute lung injury combined with Pinelliae Rhizoma Praeparatum. Food funct. 2018;9(11):5880-90. https://doi.org/10.1039/c8fo01337c.

26. Ren W, Zuo R, Wang YN, Wang HJ, Yang J, Xin SK, Han LY, Zhao HY, Han SY, Gao B, Hu H, Hu YJ, Bian BL, Si N. Pharmacokinetic-pharmacodynamic analysis on inflammation rat model after oral administration of Huang Lian Jie Du decoction. PLoS ONE. 2016;11(6): e0156256. https://doi.org/10.1371/journal. pone. 0156256.

27. Li Q, Yang Y, Zhou T, Wang R, Li N, Zheng M, Li YY, Zhang JQ, Wu F, Yang BC, Ma YM, Ma BL. A compositive strategy to study the pharmacokinetics of TCMs: Taking Coptidis Rhizoma, and Coptidis Rhizoma-Glycyrrhizae Radix et Rhizoma as Examples. Molecules. 2018;23:2042. https://doi.org/10.3390/molecules2 3082042.

28. Zhang JQ, Wang R, Zhou T, Zhao Q, Ma BL. Pharmacokinetic incompatibility of the Huanglian-Gancao herb pai. BMC Complement Med. 2020;20(1):61. https://doi.org/10.1186/ s12906-020-2845-5.

29. Meng B, Zhang ZQ. Effects of compatibility of Huanglian and Houpo on pharmacokinetics of berberine hydrochloride in rats. Chin Tradit Patent Med. 2009;31(6):943-5. https://doi.org/10. 3969/j.issn.1001-1528.2009.06.038.

30. Xie Y, Hao HP, Kang A, Liang Y, Xie T, Sun SQ, Dai C, Zheng X, Xie L, Li J, Wang GJ. Integral pharmacokinetics of multiple lignan components in normal, CCl4-induced hepatic injury and hepatoprotective agents pretreated rats and correlations with hepatic injury biomarkers. J Ethnopharmacol. 2010;131:290-9. https://doi.org/10.1016/j.jep.2010.06.038.

31. Xin GZ, Qi LW, Shi ZQ, Li P, Hao HP, Wang GJ, Shang J. Strategies for integral metabolism profile of multiple compounds in herbal medicines: pharmacokinetics, metabolites characterization and metabolic interactions. Curr Drug Metab. 2011;12(9):809-17. 